\title{
Blackboard System as an e-Learning Environment: Female students' Perceptions
}

\author{
Mona Alkhattabi \\ College of Computer Science and Information, Al Imam Mohammad Ibn Saud Islamic \\ University (IMSIU), Saudi Arabia
}

\begin{abstract}
In spite of the strong interests from nearly all universities in Saudi Arabia in implementing Learning Management System (LMS) and Information and communication technology (ICT) resources, e-learning is relatively innovative to the Saudi universities. In fact, there is a knowledge gap with regard to complete considerations of the application of e-learning methods, best practices and resources in the tertiary education division in Saudi Arabia. This study is part of a wider research project aiming to propose a framework for understanding motivators, obstacles, and enablers for successful elearning application in Saudi tertiary education sector. This study focuses on identifying the perceived e-learning barriers for female students studying in Computer Science and Information College at Al Imam Mohammad Ibn Saud Islamic University in Saudi Arabia. Moreover evaluates the relations among the identified e-learning barriers and ease of use, usefulness and satisfaction with elearning. The preliminary research findings presented here were reported based on original questionnaire data and series of linear regressions analysis. The results will be used in a series of workshops for faculty who are interested in integrating technology in their teaching. In addition, it will be used in further investigations and as a corner stone for framework building.
\end{abstract}

\section{Introduction}

Saudi Universities are increasingly using elearning solutions and LMSs as part of the teaching methods. Definition of e-learning was discussed intensely in the literature, most of the definitions look at e-learning in general. The term e-learning is used in literature and commercial applications to describe many fields such as online learning, webbased training, distance learning, distributed learning, virtual learning, or technology-based training. During the last decade, e-learning was defined in literature in different ways. In general, most definitions for e-learning are used to express the exploitation of the technologies which can be used to deliver learning (or learning materials) in an electronic format, most likely via the internet [1-4] Limited studies have been carried out regarding the use of e-learning in Saudi Universities [5-8] The majority of studies have focused on the perceptions of the instructors and students concerning the integration of new technologies into their teaching and learning. In addition, they focused on the evaluation of the effectiveness for the overall application in Saudi Universities.

This study is part of a wider research project aims to propose a framework for understanding motivators, barriers, and enablers for successful e-learning application in Saudi Universities. This paper shed some light on the perceived e-learning barriers for female students studying in Computer Science and Information College at Al-Imam Mohammad Ibn Saud Islamic University in Saudi Arabia. It also aims to evaluate the relations between the identified elearning barriers and the ease of use, usefulness and satisfaction with e-learning.

\section{Literature Review}

Although e-learning barriers were discussed in the literature in many ways and from different perspectives, there is a general agreement that the barriers could be classified into four main areas. These areas are: Information and communication technology (ICT) environment issues, student characteristics, support for students, and provision of authentic activities [9].

From a human resources perspective, e-learning is a tool for providing accessible training courses for employees. In this context, seven types of barriers to e-learning were reported in a study included 875 employees who had taken e-learning courses: personal or dispositional; learning style; instructional; situational; organizational; content suitability and technological barriers [10].

In another study which was conducted to discover barriers in integrating ICT into teaching activities from the perspective of faculty members at a UAE University, the most mentioned barriers were: poor administrative support; problems with time, access, space, supervision, and operations; poor software; curriculum integration difficulties; 
teacher's attitudes and knowledge towards computers; computer limitations and inadequate numbers of computers; and lack of technical support [11]. Moreover, one of the main (ICT) environment issues is learner's access to the internet which could be affected by many technological factors. However, technology is only one of several barriers to be considered in this regards [12].

The second perspective to be considered is student characteristics which include demographic differences in age, gender, learning styles, previous educational experience with technology, and motivation for learning in an e-learning environment. However, this study will focus on students studying in the female section of Computer science and Information College at Al-Imam Mohammad Ibn Saud Islamic University in Saudi Arabia. Most of these students have undertaken all their previous education in Arabic, speak English as a second language and their English skills level are varying. Although The Ministry of Education in Saud Arabia has taken steps towards e-learning by undertaking a number of projects, students generally have attended schools that use a traditional teaching and learning approach of teacher-centric, rote-learning and memorizations and very limited formats for learning resources [8]. In fact, in most Arabic students follows a teacher-controlled and task directed approach than would be in a western university[13]. Another important factor of student's ability to deal with the new environment of e-learning is self efficacy of learners. Mungania \& Reio described Self efficacy as a reflection of what individuals believe they can do with the skills they possess this beliefs could contribute to the success with which a task is completed. They also emphasize that learners must comprehend their personal roles and responsibilities in e-learning [14]. In fact, even that teachers and elearning facilitators must conducts many changes to the environment in terms of organization, design or technology, each student should know that in elearning environment, he has to take responsibility for his own learning[15].

One of the recognized barriers to students adapting to the online learning environment is their linguistic capability. While cultural factors had noticeable influence on students general educational experience, linguistic factors more likely to have more impact on the students' actual use of online resources [16]. Moreover, socio-cultural factors may present cultural barriers for adopting virtual learning environment because educational practices is inevitably related to culture and tradition [17].

Regarding students' support, it includes students' ability to engage with the learning activities independently, teacher competence and understanding of the pedagogy. Moreover, support for students can be consider as key to their positive experiences in an e-learning environment.
Depending in a previous study conducted in Zayed University in the UAE, main recognized barriers in this context were anxiety, technical problems, inaccessibility, and time pressure. Also, results from this study stated that online human interaction can enhance motivation and engagement in the learning process [18].

Beside the three main perspectives discussed earlier, in order to achieve an effective teaching and learning it is important to offer authentic learning tasks. In fact, learning process is complex in itself so adding online delivery means additional barriers for some students. The main recognized barrier in this area were concerns with the design, access, technological issues and the need for skills development of both teachers and learners [19]. Further research, in Saudi Arabia is required to determine whether these four barrier themes apply and also to examine the reasons why e-learning may not be readily adopted by students and faculty in the Saudi Arabia. This study aims to provide preliminary empirical evidence towards achieving this goal.

\section{Methodology}

A survey was conducted aiming to investigate female students' perspective regarding the e-learning barriers. The participants were students from College of Computer Science and Information, in Imam Mohammed bin Saud University. They were selected on a voluntary basis from fifth, sixth, seventh and eighth levels from the Computer Science, Information System and Information Study departments. Data collection was carried out February and March 2013.

The survey was performed on a sample chosen from a population of students who have already involved in courses using the Blackboard system for at least once during their study. The survey was distributed to the respondents via their account in Blackboard because of its reduced cost, decrease short transfer time and its convenience for respondents. Google doc. was used to create the survey, deploy it via e-mail, and collect respondent data. The survey was planned to take less than five minutes to complete. The survey was piloted with 5 students in January 2013 and based on the results of the pilot study; several changes were made to the survey questions to remove ambiguities.

The students were asked to rate the thirteen elearning barriers, that were identified from the literature, (summarized in Table 1) based on a 5 point Likert scale (strongly agree, agree, neutral, disagree, strongly disagree). 
Table 1 . The rate of the thirteen e-learning barriers by students

\begin{tabular}{|c|c|}
\hline B1 & [I prefer to talk to my teachers instead of using Blackboard.] \\
\hline B2 & [I would prefer to use Blackboard in my own language.] \\
\hline B3 & [Using Blackboard makes me feel stressed and anxious.] \\
\hline B4 & [Blackboard is complex and difficult to use.] \\
\hline B5 & [Blackboard is not exciting or interesting to use.] \\
\hline B6 & [The courses and materials available online are boring.] \\
\hline B7 & [I have concerns about the quality of the educational materials in Blackboard.] \\
\hline B8 & [I don't think using Blackboard helps me to learn.] \\
\hline B9 & [Using Blackboard is not the way I prefer to learn because it does not suit my learning style.] \\
\hline $\mathrm{B} 10$ & [Using Blackboard is not compatible with the way we are taught in department/college.] \\
\hline B11 & [I don't have enough time to use Blackboard.] \\
\hline B12 & [I don't feel motivated to use Blackboard.] \\
\hline B13 & [It is not cool to use Blackboard in my department/college.] \\
\hline
\end{tabular}

Moreover, they were also asked to rate ease of use, usefulness and perceived satisfaction level with e-learning based on a 5 point Likert scale (very easy/useful/satisfied, easy/useful/satisfied, neutral, difficult/ useless/ dissatisfied, very difficult/ useless/ dissatisfied). These components were integrated from the Technology Acceptance Model (TAM) [20]. We collected responses of 137 students from College of Computer Science and Information, in Imam Mohammed bin Saud University, from 3 different departments, $49.6 \%$ of the respondents were from Information System department, 35.8\% from Computer Science department and 14.6\% from Information Study department. All the students in the sample dealt with Blackboard system during their study at least for one semester. Of the respondents that contributed, the majority [38.0\%] were from level 8 students, $25.5 \%$ from level 7, 21.9\% from level $640 \%$ were holding Bachelor's degree, 33\% have Master's degree while the remaining $14.6 \%$ are students at 5 th level.

A series of linear regressions was applied to the data to determine whether ease of use, perceived usefulness or perceived level of satisfaction was associated with the perception of any of the 13 barriers.

\section{Results}

First, we conducted a frequency analysis for each variable to check for major mistakes and missing values. The results for variables frequency analysis in each dimension show that the data is valid and ready to be analyzed. Then we carried out a reliability test to check the level to which research results would be the same if the investigation was to be repeated with a different sample or at a later date. The most accepted test of inter-item consistency reliability is the Cronbach's coefficient alpha[21, 22].

Based on Sekaran reliabilities less than 0.6 are considered to be poor, those in the 0.7 range are accepTable, and those over 0.8 are good[23]. The closer to 1.0 the better the reliability coefficient is. In general, the minimum accepTable value of Cronbach's alpha is $0.70[24,25]$, but this could be reduced to 0.6 for exploratory research[26]. The Cronbach's alpha values for the recognized barriers and for the integrated components from TAM gave an accepTable reliability level with 0.893 , and 0.756 respectively. Moreover, we calculated the mean of each identified barrier in order to identify the perspective of the students in the importance of these barrier and to take a general idea of whether there is a certain order of importance to be considered. The results are shown in Table 2. 
Table 2. The mean of each identified barrier

\begin{tabular}{|c|c|}
\hline Barrier & Mean \\
\hline B1 & 1.817518248 \\
\hline B2 & 2.401459854 \\
\hline B7 & 2.95620438 \\
\hline B6 & 2.97080292 \\
\hline B9 & 3.01459854 \\
\hline B10 & 3.102189781 \\
\hline B3 & 3.138686131 \\
\hline B12 & 3.175182482 \\
\hline B5 & 3.277372263 \\
\hline B13 & 3.540145985 \\
\hline B11 & 3.729927007 \\
\hline B4 & 3.832116788 \\
\hline B8 & 4.02919708 \\
\hline & \\
\hline & \\
\hline & \\
\hline & \\
\hline & \\
\hline & \\
\hline
\end{tabular}

An interesting finding from the previous Table is that the most important barrier from student's perspective was their desire to communicate directly with the teachers while the difficulty and complexity of Blackboard or lack of a sense of its importance came in the last two ranked in terms of importance. In fact, this point is worth further research and investigations in future work because it will help in prioritizing the process of overcoming the identified barriers.

The next stage was conducting a series of linear regressions analysis, the results is demonstrated in Table 3. This Table is showing the significant results only.

\section{Discussion}

Before looking at each barrier individually, there are two important findings that should be noted. First finding, B9 (Using Blackboard is not the way I prefer to learn because it does not suit my learning style) was not statistically significantly associated with any studied component (ease of use, usefulness and satisfaction). Second, B2 is significantly negatively associated with the three studied component (ease of use, usefulness and satisfaction) which we will explain later in this section with more details.

Now we will discuss the findings related to each of the barriers in more details.

From Table 3 and by observing the positive and negative Beta values it could be noticed that "Ease of use" is negatively significantly associated with B2,
B4, B7, B8, B10 and B12. This means that those who did not find the Blackboard easy to use are more likely to prefer using the system in their own language, find the system complex, have concern regarding the quality of the educational materials within the system and do not think using Blackboard helps them to learn. They also more likely to feel that using Blackboard is not compatible with the way they were taught in their departments. Moreover, they are more likely not to feel motivated to use the system. While the same component is positively significantly associated with B1, B2, B11, B13. Which $\mathrm{s}$ indicates that those who thought Blackboard is easy to use would still prefer to talk to their teachers, feel stressed and anxious when using the system, don't have enough time to use Blackboard and they find using the system is not cool enough.

On the other hand, "Usefulness" is negatively associated with B1, B2, B5 and B8. Which means that those who find the Blackboard less useful are more likely to prefer talking to their teacher instead using the system and they also more likely to prefer using the system in their own language. Moreover, they are more likely to find the system unexciting and question whether it helps them to learn. Whereas, the same component is positively significantly associated with B3, B6 and B10. Which indicates that those that found the system useful are more likely to be stressed through its use and find the available materials to be boring. Besides, they are expected to question its compatibility with the way they are being taught.

Finally, "Perceived Satisfaction" is negatively significantly associated with B2, B7 and B12. Which shows that those who are not satisfy with the system are more likely to prefer using it in their own language and have concerns regarding the quality of educational materials distributed in the system and do not feel motivated to use it, whilst the same component is positively associated with B1 and B5. It means that those who are satisfy with the system are more likely to prefer to talk to their teachers instead using it and find the system unexciting to use.

\section{Conclusion and Implications}

The initial findings of this study highlight the importance of further research and investigation into how e-learning barriers are perceived by female students within higher education institutions in Saudi Arabia. The associations between e-learning barriers and student gender differences worth more investigations with larger sample size. On the other hands, the association between the perceived satisfaction of e-learning and e-learning barriers requires additional analysis and study. Moreover, It is quite possible that the educational and 
Table 3. Results of series of linear regressions analysis

\begin{tabular}{|c|c|c|c|c|c|c|}
\hline & $\mathbf{R}^{2}$ & Adjusted $\mathbf{R}^{2}$ & Barrier & Beta & t-value & Sig. \\
\hline \multirow{10}{*}{ Ease of use } & \multirow{10}{*}{.816} & \multirow{10}{*}{.797} & B1 & .389 & 5.477 & .000 \\
\hline & & & B2 & -.303 & -4.866 & .000 \\
\hline & & & B3 & .962 & 9.531 & .000 \\
\hline & & & B4 & -.293 & -2.835 & .005 \\
\hline & & & B7 & -.460 & -6.346 & .000 \\
\hline & & & B8 & -.198 & -3.235 & .002 \\
\hline & & & B10 & -.623 & -7.273 & .000 \\
\hline & & & B11 & .586 & 6.810 & .000 \\
\hline & & & B12 & -.650 & -6.306 & .000 \\
\hline & & & B13 & .247 & 3.381 & .001 \\
\hline \multirow{7}{*}{ Usefulness } & \multirow{7}{*}{.687} & \multirow{7}{*}{.654} & B1 & -.275 & -2.963 & .004 \\
\hline & & & $\mathrm{B} 2$ & -.301 & -3.700 & .000 \\
\hline & & & B3 & .384 & 2.921 & .004 \\
\hline & & & B5 & -.999 & -9.047 & .000 \\
\hline & & & B6 & .638 & 6.924 & .000 \\
\hline & & & B8 & -.261 & -3.277 & .001 \\
\hline & & & B10 & .409 & 3.661 & .000 \\
\hline \multirow{5}{*}{$\begin{array}{l}\text { Perceived } \\
\text { Satisfaction }\end{array}$} & \multirow{5}{*}{.739} & \multirow{5}{*}{.711} & B1 & .664 & 7.841 & .000 \\
\hline & & & $\mathrm{B} 2$ & -.254 & -3.418 & .001 \\
\hline & & & B5 & .344 & 3.411 & .001 \\
\hline & & & B7 & -.393 & -4.548 & .000 \\
\hline & & & B12 & -.543 & -4.423 & .000 \\
\hline
\end{tabular}

technological backgrounds of students will make a significant difference to their e-learning experiences. So, that side should be studied carefully and taken in to consideration before implementing the findings in different schools and colleges.

The findings of this study are anticipated to be reported to teachers and administration in higher education institutions in Saudi Arabia to help in identifying the key areas to address in relation to the use of online delivery in their courses.

In fact, the noticeable strong interest from most Saudi Universities in adopting e-learning technologies in their institutions makes it crucial to determine and address the barriers to e-learning for students and the findings of this study will help achieving this goal.

In addition, the findings will be used in further investigations and as a corner stone for to build a framework for understanding motivators, barriers, and enablers for successful e-learning application in Saudi tertiary education sector. Moreover, the results of this research will be used in a series of workshops for faculty who are interested in integrating technology in their teaching. 


\section{References}

[1] J. Gerhard and P. Mayr, "Competing in the E-learning Environment--Strategies for Universities.," in the 35th Annual Hawaii International Conference on System Sciences (HICSS'02). Hawaii, January 2002, pp. $3270-$ 3279 .

[2] P. Morten, "Online Education Systems: Discussion and definition of terms," NKI Distance Education, pp. 1-8, 2002.

[3] P. Y. and R. S., "Re-evaluating the Effectiveness of a Web-based Learning System: A Comparative Case Study.," Journal of educational multimedia and hypermedia, vol. 12, pp. 5-20, 2003.

[4] D. P. D. (1998) Learner control in asynchronous learning environments. ALN Magazine. 1-7.

[5] S. Ali, S. Sait, and K. Al-Tawil, "Perceptions about eLearning in Saudi Arabia," presented at the ICASE World Conference on Science \& Technology Education, Penang, Malaysia, 2003.

[6] M. S. Albalawi, Critical Factors Related to the Implementation of Web-based Instruction by Highereducation Faculty at Three Universities in the Kingdom of Saudi Arabia: University of West Florida, 2007.

[7] K. A.-S. Al-Harbi, "e-Learning in the Saudi tertiary education: Potential and challenges," Applied Computing and Informatics, vol. 9, pp. 31-46, 1// 2011.

[8] A. F. Algahtani. (2011). Evaluating the effectiveness of the e-learning experience in some universities in Saudi Arabia from male students.

[9] L. Vrazalic, J. Macgregor, and D. J. Behi, " E-learning Barriers in the United Arab Emirates:preliminary Results from an Empirical Investigation.," IBIMA BUSINESS REVIEW, vol. 4, pp. 1-7, 2009.

[10] M. P., "The seven e-learning barriers facing employees.," Masie Centre learning consortium.2003.

[11] S. K., "Barriers to integration in a technology rich environment.," Learning and Teaching in Higher Education: Gulf perspective,, pp. 1-24., 2005.

[12] S. D.E., "The forum report: Elearning adoption rates and barriers," in The ASTD e-learning handbook: Best practices, strategies and case studies for an emerging field, R. A., Ed., ed New York: McGraw Hill., 2002, pp. 19-23.

[13] B. J., H. F., and M. J., "Research into the use of information literacy web resources by Arabic Students.," ed. Zayed University, UAE., 2007.

[14] M. P. and T. G. J. Reio, "If E-Learners get there, will they stay? The role of e-learning self-efficacy.," ed. http://www.eric.ed.gov/ERICWebPortal/contentdelivery/se rvlet/ERICServlet?accno=ED492287 ERIC, 2005.
[15] M. S. Knowles, The adult learner: A neglected species., 4th ed. Houston, TX.: Gulf Publishing Co., 1990.

[16] H. H., "Actions and reactions: Exploring International Students' use of online information resources.," Australian academic and research libraries, vol. 36, pp. 169-179, 2005.

[17] A. A., "Web-Based Learning and Cultural Interference: Perspectives of Arab Students.," in Educatioal Media and Technology Yearbook 2005, O. M., M. J., and B. R.M., Eds., ed: Wesport, CT: Libraries Unlimited., 2005.

[18] P. M., "Motivational Constructs in an Online Learning Environment in a UAE University.," presented at the eMerging e-Learning Conference, Abu Dhabi, UAE, November 19-21, 2005.

[19] B. R., "'One size doesn't fit all": The pedagogy of online delivery in Australia," in Online learning: Research readings, G. H., Ed., ed Adelaide: National Centre for Vocational Education., 2003, pp. 55-70.

[20] D. D. Fred, "Perceived usefulness, perceived ease of use, and user acceptance of information technology," Mis q., vol. 13, pp. 319-340, 1989.

[21] L. J. Cronbach, "Coefficient alpha and the internal structure of tests," Psychometrika, Springer-Verlag, vol. 16, pp. 297-334, 1951.

[22] L. J. Cronbach, "Test validation. In R.L. Thorndike (Ed.), Educational measurement," 2nd ed. Washington, DC: American Council on Education, 1971, pp. 443-507.

[23] U. Sekaran, Research methods for business: A skillbuilding approach, 3rd ed. New York: John Wiley and Sons, 2000.

[24] J. Pallant, SPSS Survival Manual. United Kingdom: Open University Press., 2005.

[25] J. P. Peter, " Reliability: a review of psychometric basics and recent marketing practices.," Journal of Marketing Research, vol. 16, pp. 6-7, 1979.

[26] P. Robinson, R. Shaver, and S. Wrightsman, "Criteria for scale selection and evaluation. Measures of personality and social psychological attitudes. ," ed. San Diego, CA., 1991. 